\title{
The Baby and the Marriage: Identifying Factors That Buffer Against Decline in Marital Satisfaction After the First Baby Arrives
}

\author{
Alyson Fearnley Shapiro, John M. Gottman, and Sybil Carrère \\ University of Washington
}

\begin{abstract}
This longitudinal study identified factors of couples' marital friendship in the beginning months of marriage that predicted stability versus decline in marital satisfaction over the transition to parenthood. Newlywed couples $(N=130)$ were followed longitudinally for 6 years. Forty-three couples became parents, and 39 childless couples served as a control group. Couples were interviewed about the history and philosophy of their relationship as newlyweds. What predicted the stable or increasing marital satisfaction of mothers were the husband's expression of fondness toward her, the husband's high awareness for her and their relationship, and her awareness for her husband and their relationship. In contrast, what predicted the decline in marital satisfaction of mothers were the husband's negativity toward his wife, the husband's disappointment in the marriage, or the husband or wife having described their lives as chaotic.
\end{abstract}

It is well-known that half of all divorces occur within the first 7 years of marriage (Cherlin, 1981), with one third of all divorces occuring within the first 5 years of marriage (National Center for Health Statistics, 1991). For many couples, the cascade toward divorce begins with the first decline in the wife's marital satisfaction after the arrival of the first baby (Belsky \& Pensky, 1988; C. P. Cowan \& Cowan, 1992; Raush, Barry, Hertel, \& Swain, 1974). As early as 1957, Lemasters identified the transition to parenthood as one of the family's most difficult adjustments. The majority of research on the

Alyson Fearnley Shapiro, John M. Gottman, and Sybil Carrère, Department of Psychology, University of Washington.

This research was supported by Grants MH42484 and MH47083 from the National Institute of Mental Health.

We thank the undergraduate research assistants who coded the interviews we analyzed in the present study, and we gratefully acknowledge the cooperation of the study participants.

Correspondence concerning this article should be addressed to Alyson Fearnley Shapiro, Department of Psychology, University of Washington, Box 351525, Seattle, Washington 98115-1525. Electronic mail may be sent to alysonfs@u.washington.edu. transition to parenthood has found that as couples become parents, there is a dramatic decrease in positive marital interchanges, a dramatic increase in marital conflict, and a precipitous decline in marital satisfaction (Belsky \& Kelly, 1994; Belsky \& Pensky, 1988; Belsky, Spanier, \& Rovine, 1983). These findings were particularly pronounced for wives and in some cases were found only for the wives; however, the wife's declining marital satisfaction is a lead indicator of the husband's later declining marital satisfaction (Belsky et al., 1983; Waldron \& Routh, 1981).

Despite the overall decline in marital satisfaction experienced by couples as they become parents, not all couples become less satisfied with their marriages during the transition to parenthood (Wright, Henggeler, \& Craig, 1986; C. P. Cowan \& Cowan, 1988). Is it possible in the very beginning of marriage to identify buffers to this cascade toward divorce? The goal of the present study was to discover these buffers, measurable in the first few months of marriage, that predict later stability versus decline in marital satisfaction over the transition to parenthood.

In a study done by Feldman (1971), although marital satisfaction decreased in $43 \%$ of couples 
who were new parents, marital satisfaction remained stable in $39 \%$ of couples and marital satisfaction increased in $18 \%$ of couples as they became parents. C. P. Cowan and Cowan (1995) reported finding that marital satisfaction decreased in $45 \%$ of men and $58 \%$ of women, with increasing marital satisfaction in $18 \%$ of couples not participating in one of their intervention groups.

It is also important to note that remaining childless does not ensure marital stability. C. P. Cowan and Cowan (1992) reported a divorce rate of $50 \%$ for couples who remained childless but a divorce rate of $25 \%$ for couples who became parents. This is a curious finding in light of the overwhelming research indicating that a significant portion of couples experience a decline in marital satisfaction as they become parents. It is possible that a portion of the most distressed couples do not stay together long enough to start planning a family or that the transition to parenthood serves as a buffer from divorce for some couples and triggers the cascade toward divorce in others. Whatever the answer is, this is an interesting finding in need of further examination with the constellation of changes that take place as couples become parents.

Few studies on the transition to parenthood have included a control group of couples who are childless (Belsky \& Pensky, 1988). The inclusion of a childless control group is essential in discriminating changes due to the passage of time from changes characteristic of the transition to parenthood.

Unfortunately, studies that examine the transition to parenthood have primarily focused on the period from the third trimester of the wife's pregnancy to several months after the baby is born (Assor \& Assor, 1985; Belsky et al., 1983; C. P. Cowan \& Cowan, 1988). Only a handful of studies have examined the transition to parenthood from a perspective that includes a time period before the wife's pregnancy (Crawford \& Huston, 1993; McHale \& Huston, 1985; Raush et al., 1974). This is highly unfortunate because Raush et al. demonstrated that the nature of the marriage has already changed dramatically once the wife is pregnant. Raush et al. found that husbands were more conciliatory during their wives' pregnancies than either before pregnancy or after the birth of the child. For empirical research on the prevention of the decline in marital quality after the baby arrives, it is first necessary to identify any potential buffers before the couple becomes pregnant. The goal of the present study was to begin examining couples not only at a time point before pregnancy but also from the very beginning of their marriage as newlyweds. Is there anything in the early months of newlywed marriages that can predict whether a couple's marriage will be at risk for decline once the first baby arrives?

Additionally, few studies following couples longitudinally as they become parents include time points several years after the birth of the first child (Belsky \& Rovine, 1990; P. A. Cowan, Cowan, \& Kerig, 1993). Because of many serious artifacts in the data analyses of change, Rogosa (1995) strongly urged longitudinal investigators to use multiple time points (rather than just two) and analyze the pattern of change over time. He urged the use of repeated measurement to examine the pattern of change over time through growth curve modeling.

These considerations imply that studies should include a time point before pregnancy and then follow couples for several years to accurately examine the impact of the pregnancy and the birth of the first child on the couples' changing satisfaction with their marriage. The present investigation was designed with these considerations in mind.

One study that did include a time point before pregnancy followed a sample of newlyweds over the transition to parenthood (MacDermid, Huston, \& McHale, 1990; McHale \& Huston, 1985). Sixty-nine couples married for the same length of time were followed over the same 2-year period of time. The 43 couples who remained childless provided an accurate comparison group for the 23 couples who became parents. MacDermid et al. found no significant differences in marital satisfaction between the control group and the parent group. They concluded that marital satisfaction declines equally for couples who become parents and for those who remain childless. These results contradict the findings in the majority of other transition to parenthood research, which indicate there is a decline in wife marital satisfaction over the transition to parenthood. The critical differences may be a lack of power to detect results with only 23 couples who become parents or the relatively short time span for which the couples were followed. A longitudinal 
study of couples over only the first 2 years of marriage would not be able to detect trends that indicate decline several years after the birth of the first child. The present investigation was designed with these considerations also taken into account.

We examined the possibility that the way couples conceptualize their marriage may predict how marital satisfaction changes over time after the arrival of the baby. In our laboratory, Krokoff (1984) had developed the Oral History Interview (OHI), which queries couples about the beginnings of their relationship, their philosophy of marriage, and how their relationship has changed over time. We subsequently found that behavioral coding of this interview predicted stability versus divorce in marriages with 94\% accuracy (Buehlman, Gottman, \& Katz, 1992 ) and with $88 \%$ accuracy in the sample of newlyweds used in the present study (Carrère, Buehlman, Coan, Gottman, \& Ruckstuhl, 2000). The OHI predictors of marital stability were the fondness and admiration expressed by each spouse for his or her partner, the amount of expansiveness and awareness of their partner's world, and the amount of unity expressed by each spouse through his or her use of the words we and us. OHI predictors of divorce were the amount of criticism or negativity each spouse expressed toward their partner, the extent to which they were disillusioned or disappointed about the marriage, and the extent to which they felt that difficulties in their lives were out of their control or were chaotic.

We view these $\mathrm{OHI}$ predictors as indices of the quality of the early marital friendship. Several of our OHI variables are similar to concepts that have been examined over the transition to parenthood by other researchers. The unity in the marriage, or we-ness, measured in the OHI, for example, is similar to a concept Belsky and Kelly (1994) referred to as the ability of couples to integrate themselves into "us." The expansiveness or awareness that each spouse has for his or her partner and their relationship, tapped by our $\mathrm{OHI}$, is similar to the intimate knowledge base of one's spouse that Belsky described as being important for maintaining good communication as couples become parents (Belsky \& Kelly, 1994).

The OHI is coded on the basis of how the couple describes their relationship and the coding emphasizes attitude over content in what the couples say (Buehlman \& Gottman, 1996). The $\mathrm{OHI}$ is different from interviews used in other transition-to-parenthood studies in that it serves as observational data rather than as a self-report measure. The measure has high external construct validity, illustrated through the significant relationship of the coding dimensions with observations of the couples' problemsolving behavior, affect, and physiology during marital interactions (Buehlman et al., 1992).

The present study is unique in that it sought to predict changes in a couple's marital satisfaction and to identify buffers during the transition to parenthood on the basis of the couple's relationship as newlyweds. We tested the hypothesis that the way couples describe their past predicts stability versus decline in marital satisfaction as couples become parents. Specifically, we hypothesized that the way a couple conceptualizes the beginnings of their relationship would reveal strengths and vulnerabilities in the marriage. Our hope was that these strengths would turn out to be buffers that predict resilience through this major developmental life transition.

\section{Method}

\section{Participants}

Between 1989 and 1992, we used a two-stage sampling procedure to draw a representative sample of newlywed couples from the Puget Sound area in Washington. Couples were initially recruited using newspaper advertisements. Couples were eligible for the study if they were childless and had been married for the first time within 9 months of first participating in the study. Couples were contacted by phone and administered the telephone version of the Marital Adjustment Test (MAT; Krokoff, 1984; Locke \& Wallace, 1959) and surveyed to determine their eligibility.

Newlywed couples $(N=130)$ who represented an even distribution of marital satisfaction were invited to participate in a longitudinal study of their marriage and were followed for the next 4 to 6 years. The racial and ethnic distribution in this sample matched the City of Seattle, Office of Long-Range Planning (1990) commission report. Demographic characteristics for these newly married couples were as follows: mean wife age $=25.4$ years $(S D=3.5)$, average husband age $=26.5$ years $(S D=4.2)$, average wife marital satisfaction $=120.4(S D=19.7)$, and mean husband marital satisfaction $=115.9(S D=18.4)$.

The average wife marital satisfaction was significantly higher than the average husband marital satisfaction, $t(128)=2.63, p=.01$. A review of the 
literature revealed no statistics on mean marital satisfaction differences expected or not expected when couples are newlyweds. A report examining data from the National Survey of Families and Households noted that marital satisfaction is usually lower for wives than for husbands (Schumm, Webb, \& Bollman, 1998). Schumm et al., however, examined a cross-section of married couples and most were married several years and had gone through the transition to parenthood. Thus, their results could actually be consistent with ours if wives' martial satisfaction begins on average at a higher level than their husbands' and drops to a level lower than their husbands' across the transition to parenthood. Further research is needed to confirm whether this sample is typical or unique with regard to this difference in initial marital satisfaction.

Forty-three of these couples became parents during the years they were followed. The control group $(n=39)$ was composed of couples from the same cohort of newlyweds who remained childless and married during this same time period. Instances for which results are reported with smaller numbers are instances in which coding on a specific dimension or a specific marital satisfaction questionnaire was missing for some couples.

The 49 couples in our original sample of 130 who were not included in either the sample of couples that became parents or the sample of couples that remained childless were excluded for a variety of reasons. Six couples from the original sample of newlyweds were excluded because they were expecting their first baby during the time of data analyses and were considered to be in the midst of their transition. Additionally, if couples completed fewer than three marital satisfaction questionnaires over the time they were followed or if there were no postbirth data for couples who became parents, they were excluded from the regression analysis. Thus, 15 couples who divorced within the first 3 years of their marriage were excluded. There were 17 divorces during the time couples were followed, all in the group who remained childless. Three of these divorced families were included in the control group. Two couples were excluded because they dropped out of the study within the first 3 years, 1 couple was excluded because of the death of the husband, and 25 couples were excluded because of missing questionnaire data. Couples that were excluded because of missing questionnaire data were not significantly different from the other couples in our sample on the demographic variables of age, socioeconomic status (SES), level of education, and initial husband and wife marital satisfaction level.

There were no significant demographic differences between newlyweds who became parents and newlyweds who became part of the control group on age, SES, level of education, or initial husband marital satisfaction. Average initial marital satisfaction was significantly higher for wives who became mothers $(M=126.88)$ than for wives who remained childless $(M=119.87), t(79)=2.07, p=.04$. Couples who became parents had their first child on average 3.07 years after the beginning of their marriage $(S D=1.08)$. Consistent with the overall newlywed sample, marital satisfaction was significantly higher for wives who became mothers $(M=126.26)$ than for husbands who became fathers $(M=119.88)$, $t(41)=2.30, p=.03$, and marital satisfaction was significantly higher for wives who remained childless ( $M=119.87$ ) than for husbands who remained childless $(M=113.95), t(38)=2.38, p=.02$.

\section{Procedure}

Couples were given the OHI, which is a semistructured interview with open-ended questions asking couples to tell the story of their relationship's history, and their philosophy of marriage (Krokoff, 1984). The $\mathrm{OHI}$ was conducted with newlywed couples during their 1st year of marriage in one of two settings. A subset of 50 couples was selected to be studied in more detail and spent $24 \mathrm{hr}$ in a studio apartment laboratory. For logistic and financial reasons, we did not include all 130 couples in this procedure. Couples were interviewed after dinner in the living room area of the apartment laboratory. These interviews were videotaped. Couples who did not come in for this component of the study were interviewed in their homes, and these interviews were audiotaped. Thirty-four of the couples interviewed in the apartment laboratory and 34 of the couples interviewed at home were included in the 82 couples selected for the present study. A multivariate analysis of variance (MANOVA) was used to examine differences in OHI coding between these two groups. Using Wilks's lambda as a criterion, we did not find any significant differences, $F(11,60)=1.27$, ns. The setting in which the OHI was conducted did not appear to have an impact on interview content or scoring of the interview.

\section{Longitudinal Follow-Ups}

Couples were contacted by both phone and mail each year following their initial visit. They were interviewed about their marital status, and anticipated or actual births in their families and asked to complete a questionnaire on marital satisfaction (the MAT; Locke \& Wallace, 1959) that was mailed to their homes. Administration of the MAT questionnaires were timed such that couples who became parents were administered additional marital satisfaction questionnaires when the wife in each couple was 6 months pregnant and when their first baby was 3 months old. Thus, couples recruited in 1989 completed up to eight MAT questionnaires if they became 
parents and up to six questionnaires if they remained childless. Couples recruited in 1991 completed up to six MAT questionnaires if they became parents and up to four questionnaires if they remained childless.

\section{Measures and Materials}

$O H I$. The $\mathrm{OHI}$ is conducted with both the husband and wife present, and both spouses are encouraged to give their perspective on all aspects of their relationship history. The interview takes about 1 hr. Questions about the couples relationship history focus on the couple's courtship, their decision to marry, their wedding, and the highlights and difficult times in their relationship. When the couple discusses their philosophy of marriage, they are asked to think of a good marriage and a bad marriage and to discuss the differences between these kinds of marriages (Buehlman et al., 1992). The questions that compose the interview can be found in Buehlman and Gottman (1996).

$\mathrm{OHI}$ coding. The Oral History Coding System (Buehlman \& Gottman, 1996) was used to code the OHI across six dimensions with 11 subscales designed to capture the couples' global perceptions about the marriage and about each other. Five of the six dimensions are rated on an individual basis and the final dimension is rated for the couple as a whole. Each subscale is made up of five to nine items. Each item is scored using a 5-point Likert-like scale ranging from 1 (strongly agree) to 5 (strongly disagree). Items are identical for the husband and the wife in the dimensions that are scored individually. Correlations between subscales ranged from .55 to .92. Subscales were positively correlated within positive and negative categories, and positive and negative subscales were negatively correlated (see Table 1).

Three of the dimensions are positive in nature: (a) Fondness/Affection, (b) We-ness, and (c) Expansive- ness. Fondness/Affection (husband and wife each get rated separately, but items are identical for both husband and wife) rates each spouse's expression of pride, fondness, and affection for his or her partner. This subscale includes items such as "Husband compliments wife during the interview" (husband's subscale) and "Wife is proud of her husband or specific qualities about her husband" (wife's subscale). We-ness (husband and wife each get rated separately, but items are identical for both husband and wife) reflects the degree to which each spouse uses terms during the interview that indicate unification in the marriage. Examples of items from this subscale include "Wife emphasizes we as opposed to he or I" (wife's subscale) and "Husband emphasizes the same beliefs, values, and goals as his wife" (husband's subscale). Expansiveness (husband and wife are each rated separately, but items are identical for both husband and wife) measures how expressive and expansive each spouse is in the interview. Through this elaboration, each spouse illustrates how aware he or she is about the details of their relationship history and about their spouse's world. We think this awareness may refiect the amount of cognitive room each spouse has for his or her partner. This dimension indexes not only how expressive each spouse is but also how the spouse responds to and expands on what his or her partner is saying. This is in contrast to spouses who respond to questions with just a few short sentences, seem withdrawn, and do not add to what their partner says. Some examples of items for this dimension include "Wife recalls easily their first date, proposal, wedding, etc." (wife's subscale) and "Husband expands on what his wife is describing or saying" (husband's subscale).

Two of the coding dimensions are negative in nature: (a) Negativity (husband and wife are each rated separately, but items are identical for both husband and wife) and (b) Disappointment and Disillusionment (husband and wife are each rated

Table 1

Correlations Between Oral History Interview Coding Subscales

\begin{tabular}{lrrrrrrrrrrr}
\hline & 1 & 2 & 3 & 4 & 5 & 6 & 7 & 8 & 9 & 10 & 11 \\
\hline 1. Husband Fondness & \multicolumn{1}{c}{. } & & & & & & & & & & \\
2. Husband Expansiveness & .80 & - & & & & & & & & \\
3. Husband We-ness & .74 & .70 & - & & & & & & & \\
4. Husband Negativity & -.71 & -.59 & -.65 & - & & & & & & \\
5. Husband Disappointment & -.79 & -.75 & -.81 & .74 & - & & & & & \\
6. Wife Fondness & .84 & .74 & .67 & -.60 & -.75 & - & & & & \\
7. Wife Expansiveness & .74 & .85 & .68 & -.56 & -.70 & .82 & - & & & \\
8. Wife We-ness & .72 & .64 & .92 & -.62 & -.79 & .73 & .68 & - & & \\
9. Wife Negativity & -.65 & -.57 & -.63 & .80 & .73 & -.68 & -.55 & -.65 & - & \\
10. Wife Disappointment & -.77 & -.76 & -.81 & .67 & .91 & -.76 & -.78 & -.79 & .67 & - & \\
11. Chaos & -.68 & -.62 & -.73 & .74 & .82 & -.67 & -.63 & -.71 & .74 & .82 & - \\
\hline
\end{tabular}

Note. All correlations are significant at $p<.001$, two-tailed. 
separately, but items are identical for both husband and wife). Negativity indexes the extent to which each individual of the couple is critical of their partner, vague about what attracted them to their spouse, and displays negative affect toward their mate. Some examples of the items used to code this subscale include "Husband does not know what attracted him to his wife" (husband's subscale) and "Wife disagrees with husband during the interview" (wife's subscale). Disappointment and Disillusionment assesses the degree to which each member of the couple has given up on their marriage by expressing depression about the relationship or not being able to articulate what makes the marriage work. Some examples of items used to index this subscale include "Husband is depressed when talking about his marriage" (husband's subscale) and "Wife mentions how difficult their marriage is or marriage in general is" (wife's subscale).

Information about how the couple reports handling marital conflict was evaluated using the final dimension, Chaos (one score per couple). Chaos rates the degree to which the couple feels out of control of their lives and buffeted about by elements outside of their control. Examples of items used to assess this subscale include "The couple has a lot of unexpected or out of control marital conflict" and "The couple believe unexpected problems have weakened their relationship."

Reliability for the oral history coding was indexed by intraclass correlations. Intercoder reliability was calculated using intraclass coefficients. Overall reliability of the OHI coding subscales was .75. The intraclass correlations for the subscales in the $\mathrm{OHI}$ were as follows: Husband's Fondness, .76; Wife's Fondness, .76; Husband's We-Ness, .71; Wife's We-Ness, .76; Husband's Expansiveness, .47; Wife's Expansiveness, .66; Husband's Negativity, .81; Wife's Negativity, .71; Husband's Disappointment and Disillusionment, .79; Wife's Disappointment and Disillusionment, .72 ; and Chaos, .68 .

MAT. The MAT (Locke \& Wallace, 1959) is a highly reliable and valid measure used to index marital satisfaction. Higher scores on the MAT represent greater marital satisfaction. A telephone interview version of the MAT with similar psychometric properties to the questionnaire was first administered to the wives during the participant recruitment phase of the study (Krokoff, 1984). A questionnaire form of the MAT was used to index marital satisfaction each year of the couples' marriages.

Measures of change in marital satisfaction over time and intercept. Marital satisfaction scores from the MAT were regressed over time separately for the husband and wife within each couple. The resulting slopes from these regressions, or basic growth curves, reflected the rate of change over time for each husband and wife. These slopes became our variable for rate and direction of change in marital satisfaction.
Each regression over time also yielded a $y$-intercept, where the marital satisfaction slope crossed the $y$-axis. The $y$-intercepts were used in our analysis as a measure of expected marital satisfaction when each couple first became married. Figure 1 illustrates this procedure for 1 of the participants in this study.

\section{Results}

There were 17 divorces in the group of couples who remained childless and no divorces in the group of couples who became parents. Wives who became mothers had significantly sharper rates of declining marital satisfaction over time ( $M=-10.63$ points per year) than did wives who remained childless $(M=-1.12$ points per year), $t(80)=2.15, p=.04$, twotailed. Additionally, wives who became mothers, on average, had significantly higher marital satisfaction scores as newlyweds $(M=126.88)$ than did wives who remained childless $(M=119.87), t(79)=2.07, p=.04$. There was a trend toward steeper decline in marital satisfaction for husbands who became fathers that was not significant. Thus, we restricted further analyses to the group of wives. See Table 2 for slope and marital satisfaction figures.

Within the couples who experienced the transition to parenthood, marital satisfaction declined for $67 \%$ of the wives and remained stable or increased for $33 \%$ of the wives. In contrast, only $49 \%$ of the wives who remained childless had a declining trend in marital satisfaction, and $51 \%$ of the wives had stable or increasing marital satisfaction.

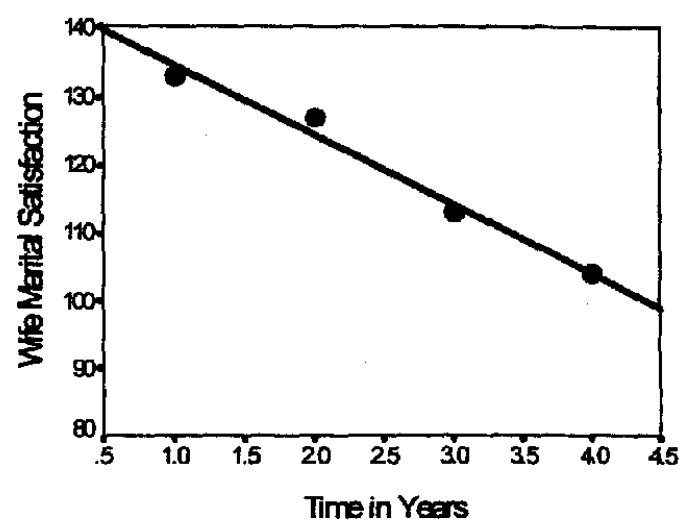

Figure 1. Rate of change of wife marital satisfaction over time. 
Table 2

Independent Sample t-Test Results Comparing Average Rate of Change in Marital Satisfaction Over Time (Slopes) and Initial Marital Satisfaction Scores in Couples Who Became Parents and Who Remained Childless

\begin{tabular}{lcccr}
\hline & \multicolumn{2}{c}{ Group mean } & & \\
\cline { 2 - 4 } \multicolumn{1}{c}{ Measure } & Parent & Childless & $t$ & $d f$ \\
\hline Slope & -10.63 & -1.12 & $2.15^{*}$ & 80 \\
$\quad$ Wife & -5.28 & -3.00 & 0.49 & 78 \\
$\quad$ Husband & & & & \\
Initial marital satisfaction & 126.88 & 119.87 & $2.07^{*}$ & 79 \\
$\quad$ Wife & 119.77 & 113.95 & -1.51 & 76 \\
$\quad$ Husband & & &
\end{tabular}

Note. All analyses were two-tailed.

${ }^{*} p \leq, 05$, two-tailed.

A decline in marital satisfaction for wives who became mothers was not always evident in our first postbirth measure 3 months after the birth of the first child. Indeed, 13 out of the 27 mothers who had a declining trend in marital satisfaction did not report this decline until 1 year after the birth of their first child, and 4 of these mothers did not show a decline until 2 years after the birth of their first child. No significant difference was found between the mean prebirth wife marital satisfaction $(M=$ 124.65) and marital satisfaction for these mothers 3 months after the birth of their first child $(M=122.64), t(32)=-0.78, p=.44$. The first significant decline in marital satisfaction for the mothers who showed a declining trend was evident about 1 year after the birth of the first child, $t(24)=-3.36, p=.002$.

\section{Predicting Change in Wife Marital Satisfaction Over Time}

Wives who became mothers had relatively stable or increasing marital satisfaction during the transition to parenthood if in the $\mathrm{OHI}$ the husband expressed fondness and affection toward his wife, the husband expressed high awareness for his wife and their relationship through expansiveness, or the wife expressed high awareness for her husband and their relationship (see Table 3). In contrast, there was a steeper decline in marital satisfaction for wives who became mothers if, in the $\mathrm{OHI}$, the husband expressed negativity toward the wife, the husband expressed disappointment in the marriage, or both the husband and the wife felt their lives were chaotic.
There were several $\mathrm{OHI}$ variables that approached significance in predicting stability versus decline in marital satisfaction. Unity, or we-ness, expressed by either the husband or the wife approached significance in predicting stable or increasing marital satisfaction for wives who became mothers. Wife disappointment approached significance in predicting decline in marital satisfaction for wives who became mothers (see Table 3). No significant relationships were found between the $\mathrm{OHI}$ variables and rate of change in marital satisfaction over time for wives who remained childless (see Table 3).

Table 3

Pearson's Correlation Coefficients of Oral History Interview (OHI) Dimensions With the Rate of Change in Wife Marital Satisfaction Over Time

\begin{tabular}{lcc}
\hline \multicolumn{1}{c}{ OHI subscale } & $\begin{array}{c}\text { Mothers } \\
(n=40)\end{array}$ & $\begin{array}{c}\text { Childless wives } \\
(n=34)\end{array}$ \\
\hline Husband Fondness & $.33^{*}$ & $-.32 \dagger$ \\
Wife Fondness & .13 & -.14 \\
Husband Expansiveness & $.33^{*}$ & .16 \\
Wife Expansiveness & $.31^{*}$ & -.005 \\
Husband We-ness & $.26 \dagger$ & -.04 \\
Wife We-ness & $.27 \dagger$ & .10 \\
Husband Negativity & $-.40^{* *}$ & .29 \\
Wife Negativity & -.22 & .28 \\
Husband Disappointment & $-.35^{*}$ & .10 \\
Wife Disappointment & $-.28 \dagger$ & .12 \\
Chaos in the Relationship & $-.33^{*}$ & .10 \\
\hline
\end{tabular}

Note. All analyses were two-tailed.

$\dagger p \leq .10$, two-tailed (marginally significant). $\quad{ }^{*} p \leq$ .05 , two-tailed. $\quad{ }^{* *} p \leq .01$, two-tailed. 
Growth Curve Analysis:

\section{Accounting for Variation in Wife Slope and Intercept Within Groups}

For the group who remained childless, there was no significant decline in wife marital satisfaction. Hence, within this group we sought to account for variation in the intercept of the wife's marital satisfaction, controlling for variation in the wife's slope. First, we examined the husband model. In a regression analysis, the husband's positivity (sum of we-ness, fondness, and expansiveness) and the husband's negativity (disappointment, negativity, and chaos) were significantly related to the wife's marital satisfaction intercept, controlling for differences in the slope of the wife's marital satisfaction, $F(3$, $29)=5.10, p=.013$. The partial correlations (for husband's positivity, $p r=.34, t[29]=$ $-1.98, p=.057$; for husband's negativity, $p r=$ $-.49, t[29]=-3.09, p=.004$ ) showed that the major contribution was the husband's negativity. Next we examined the wife model. In a regression analysis, the wife's positivity (sum of we-ness, fondness, and expansiveness) and the wife's negativity (disappointment, negativity, and chaos) were significantly related to wife's marital satisfaction intercept, controlling for differences in the slope of the wife's marital satisfaction, $F(3,29)=7.50, p=.0024$. The partial correlations (for wife's positivity, $p r=$ $.31, t[29]=2.95, p=.0062$; for wife's negativity, $p r=-.37, t[29]=-3.60, p=.0011$ ) showed that the contribution was both the wife's positivity and the wife's negativity.

For the group who became parents, there was a significant decline in wife marital satisfaction. Hence, within this group we sought to account for variation in the slope of the wife's marital satisfaction, controlling for variation in the wife's intercept. First, we examined the husband model. In a regression analysis, the husband's positivity (sum of we-ness, fondness, and expansiveness) and the husband's negativity (disappointment, negativity, and chaos) were significantly related to the wife's marital satisfaction slope, controlling for differences in the intercept of the wife's marital satisfaction, $F(3$, $35)=4.35, p=.021$. The partial correlations (for husband's positivity, $p r=.31, t[35]=2.12$, $p=.041$; for husband's negativity, $p r=-.42$, $t[35]=-2.99, p=.005$ ) showed that the con- tribution was both the husband's positivity and the husband's negativity.

Next, we examined the wife model. In a regression analysis, the wife's positivity (sum of we-ness, fondness, and expansiveness) and the wife's negativity (disappointment, negativity, and chaos) were marginally related to wife's marital satisfaction slope, controlling for differences in the intercept of the wife's marital satisfaction, $F(3,29)=2.49, p=.0975$. The partial correlations (for wife's positivity, $p r=$ $.25, t[29]=1.64, n s$; for wife's negativity, $p r=-.33, t[29]=-2.26, p=.0298)$ showed that the only significant contribution was the wife's negativity. Equivalent analyses within the group of parents attempting to account for variation in the wife's marital satisfaction intercept, controlling for her marital satisfaction slope, proved nonsignificant (for husband model, $F[3,35]=1.73, n s ;$ for wife model, $F[3$, $35]=1.21, n s)$.

\section{Discussion}

The primary goals of this study were to predict changes in marital satisfaction and to identify buffers that protect a couple during the transition to parenthood on the basis of the couple's early relationship as newlyweds. We first examined change in marital satisfaction over the transition to parenthood, confirming that there were both wives who experienced a decline in marital satisfaction and wives whose marital satisfaction remained stable during this transition. We then tested our hypothesis that the way couples describe their past would reveal strengths and vulnerabilities that would predict stability versus decline in marital satisfaction as the couples became parents.

The majority of research on the transition to parenthood has found that as couples become parents, positive interchange between the husband and the wife decreases, conflict increases, and overall marital satisfaction decreases (Belsky \& Pensky, 1988; Belsky et al., 1983). These findings were particularly pronounced for the wives and in some cases were only found for the wives (Belsky et al., 1983; Waldron \& Routh, 1981). The examination of one sample of newlyweds, however, found no significant differences in marital satisfaction between the control group and the parent group (MacDermid et al., 1990; McHale \& Huston, 1985).

In the present study, following newlyweds 
through the transition to parenthood, we found a significantly steeper decline in marital satisfaction for wives who became mothers relative to wives who remained childless. These results support the majority of previous findings that there is a systematic decline in marital satisfaction over the transition to parenthood that is particularly pronounced for the wives. This is particularly interesting in light of our finding that the wives who became mothers started out with higher marital satisfaction than did wives who remained childless. This reflects the fact that the higher initial marital satisfaction is, the farther it has to fall. Additionally, this finding suggests that wives who start out more satisfied with their marriage are more likely to have children within the first 4 to 6 years of their marriage.

The design of this newlywed study appears similar to that of MacDermid et al. (1990). Why, then, did we find a significant decline in wife marital satisfaction when MacDermid and her associates did not? These differences in results could be due to a difference in the power to detect results. We were more likely to detect significant differences between groups with a sample of 43 couples who became parents than MacDermid et al. were with the 23 couples who became parents in their study. However, close inspection of our data shows that the lowest marital satisfaction scores for wives who became mothers were often obtained a year or more after the birth of the first child rather than at 3 months postbirth. This suggests that differences in outcomes between the two studies may be the result of the amount of time couples were followed. MacDermid et al. followed couples over only the first 2 years of marriage and would not have been able to detect trends 1 to 2 years after the birth of the first child.

Despite the overall decline in marital satisfaction experienced by couples as they become parents, not all couples become less satisfied with their marriages through the transition to parenthood (MacDermid et al., 1990; McHale \& Huston, 1985; Wright et al., 1986). For couples who became parents in the present study, marital satisfaction declined for $67 \%$ of the wives and remained stable or increased for $33 \%$ of the wives.

Scores on the $\mathrm{OHI}$ administered to couples within the first few months of their marriage predicted stability versus decline in wife marital satisfaction over the transition to parenthood. Specifically, husband fondness and admiration toward the wife, the awareness or cognitive room the husband allocated to the wife and to their relationship, and the awareness or cognitive room the wife allocated to the husband predicted stability in marital satisfaction for wives who eventually became mothers. In contrast, husband negativity toward the wife, husband disappointment in the marriage, and a view that the couples' lives were chaotic all predicted a decline in marital satisfaction for wives who became mothers.

The $\mathrm{OHI}$ variables can be viewed as dynamic variables that index the marital friendship. The quality of the marital friendship acts to make stressful periods, such at the transition to parenthood, either smoother or more difficult to navigate. Fondness and admiration and high expansiveness or awareness may act as buffers that protect the relationship through stressful transitions such as the birth of the couples' first child. Disappointment in the marriage, negativity toward one's spouse, and chaos in the lives of the couple may reflect vulnerabilities in the relationship that become particularly problematic during periods of stress such as the transition to parenthood. Strategies used by consistently satisfied couples may be useful for others in maintaining marital satisfaction.

The fondness and admiration system in a couple's relationship can be thought of as the glue that holds the relationship together. Expansiveness can be thought of as the level of awareness each spouse has of their relationship, their spouse, and their spouse's life. The more fondness for his wife the husband expresses, or the more glue he puts into the relationship, the more satisfied the wife is with the marriage over the transition to parenthood. The more aware each partner is of their relationship and their partner, again, the more satisfied the wife is with the marriage over the transition to parenthood. These two factors may work together. If the husband is aware of the stress the wife is going through, for example, he may respond by putting more glue into the relationship or expressing more fondness toward his wife. Similarly, if the wife is aware of the efforts her husband is making to be supportive and loving through this transition, the more satisfied she will be with the marriage.

The unity, or we-ness, in the relationship 
expressed by either the husband or the wife only approached significance in predicting stability or increase in marital satisfaction for wives who became mothers. This is somewhat surprising because Belsky and Kelly (1994) described the couples" ability to integrate into "us" as being important over the transition to parenthood. The couples' ability to view themselves as a unit may change through the struggles of the transition to parenthood, and the emergent sense of unity may be more important than the one the husband and wife expressed as newlyweds.

Negativity and criticism can be viewed as corrosive factors that eat away at the quality of the marriage. Disappointment in the marriage is fairly straightforward and may be the cause of criticism and negativity. Wives may be particularly sensitive to their husbands' negativity and marital disappointment as they become parents and may become less satisfied with their marriage in response to these corrosives during this transition. The feeling of chaos expressed by couples reflects a belief that there are changes in their lives that are out of their control. It makes sense that this outlook would reflect a vulnerability in the relationship over the transition to parenthood because the added stresses that accompany this major life transition could increase these feelings of chaos.

The $\mathrm{OHI}$ variables were related to the marital satisfaction intercepts of wives who remained childless and the slopes of wives who became mothers. It makes sense that an index of the marital friendship would relate to the wife's marital satisfaction around the time of the interview, as is evident in the control group. In the group of wives who became mothers, however, there was a stronger relationship between the slope of wife marital satisfaction and the OHI variables than between the slope of wife marital satisfaction and the initial marital satisfaction scores. This indicates that the quality of marital friendship is particularly important during periods of change and stress, such as the transition to parenthood.

Both the husband's and the wife's OHI variables were important in predicting the intercept of wife marital satisfaction in couples who remained childless. In contrast, the variables that reflected the husband's contribution to the marital friendship were the strongest in predicting the rate of change in mother marital satisfaction over time. This indicates that the contribution of the husband to their relationship is particularly important to wives during periods of stressful transitions.

C. P. Cowan and Cowan (1992) reported a divorce rate of $50 \%$ for couples who remained childless versus a divorce rate of $25 \%$ for couples who became parents. The results of the present study revealed this trend more dramatically, with all 17 divorces in the sample occurring in the group of couples who remained childless. The divorce rate for couples in our sample who remained childless was $20 \%$, and the divorce rate for couples in our sample who became parents was $0 \%$. This indicates that remaining childless is not an adequate buffer against divorce. It also indicates that couples who remain married longer are more likely to have children.

The $\mathrm{OHI}$ is a good predictor of stability versus decline in marital satisfaction for wives who become parents. This is particularly true in comparison with the group of couples who remained childless. This finding is especially salient for mothers in contrast to fathers because the transition is particularly stressful for the wives (Belsky \& Pensky, 1988). The strength of the $\mathrm{OHI}$ in predicting stability versus decline in marital satisfaction for wives over the transition to parenthood supports our hypothesis that it taps relationship buffers and vulnerabilities.

This study is limited by its correlational nature. The relationships that have been found between predictors and outcome cannot be interpreted as causal. Subsequent research using clinical trials that manipulate change in the $\mathrm{OHI}$ variables and measuring marital satisfaction outcomes is needed to clarify the nature of the relationship between the $\mathrm{OHI}$ variables and change in marital satisfaction over periods of transition.

Subsequent research should assess how the couples' view of their marriage changes or stays the same through the transition. This could be accomplished by giving couples multiple semistructured interviews, initially to newlyweds, later to couples when they are expecting the birth of their first child, and again after the baby is born. These interviews, coded along the same dimensions, would reveal consistency versus change in these marital qualities over time. The rate of change over time in the $\mathrm{OHI}$ coding could be compared with the rate of change over 
time in marital satisfaction to yield better understanding of how these factors influence each other.

\section{Implications for Application and Public Policy}

The variables in our study predicting marital stability during the transition to parenthood (fondness and admiration for one's spouse and the awareness or cognitive room allocated to one's partner and the relationship) reflect the couple's marital friendship and their bond with one another. The variables in our study predicting decline in marital satisfaction during the transition to parenthood (negativity toward one's spouse, disappointment in the marriage or in one's spouse, and the chaos of feeling that changes are outside of the couple's control) reflect vulnerabilities in the marriage. The results of our research indicate that this marital friendship acts as a buffer during stressful times in the marriage, such as the transition to parenthood. Strengthening the marital friendship is something that both therapists and therapeutic programs could focus on to help couples becoming parents. Intervention programs designed to help couples nurture and build these protective factors of marital friendship, while simultaneously reducing vulnerabilities, may aid those at risk for turbulence and decline in marital quality during the transition to parenthood.

There has been a wealth of research indicating that as couples become parents they experience a decline in marital satisfaction, a decrease in positive interchange, and an increase in conflict (Belsky \& Kelly, 1994; Belsky \& Pensky, 1988; Belsky et al., 1983; C. P. Cowan \& Cowan, 1992, 1995). The results of the present study support the finding that marital satisfaction decreases in couples as they become parents. Despite this overwhelming evidence, there are few programs available to help couples navigate this stressful period and few studies. that have examined the effects of an intervention on marital resilience during the transition to parenthood (Clulow, 1982; C. P. Cowan \& Cowan, 1992). We advocate policy that supports further research on interventions designed to aid couples becoming parents and on the implementation of effective and available intervention programs.

\section{References}

Assor, A., \& Assor, T. (1985). Emotional involvement in marriage during the last trimester of pregnancy: $A$ comparison of husbands and wives. Journal of Psychology, 119, 243-252.

Belsky, J., \& Kelly, J. (1994). The transition to parenthood: How a first child changes a marriage. Why some couples grow closer and others apart. New York: Dell.

Belsky, J., \& Pensky, E. (1988). Marital change across the transition to parenthood. Marriage and Family Review, 12, 133-156.

Belsky, J., \& Rovine, M. (1990). Patterns of marital change across the transition to parenthood: Pregnancy to three years postpartum. Journal of Marriage and the Family, 52, 5-19.

Belsky, J., Spanier, G., \& Rovine, M. (1983). Stability and change in a marriage across the transition to parenthood. Journal of Marriage and the Family, 45, 567-577.

Buehlman, K. T., \& Gottman, J. M. (1996). The Oral History Coding System. In J. Gottman (Eds.), What predicts divorce: The measures (pp. OH11OH118). Hillsdale, NJ: Erlbaum.

Buehlman, K. T., Gottman, J. M., \&\& Katz, L. F. (1992). How a couple views their past predicts their future: Predicting divorce from an oral history interview. Journal of Family Psychology, 5, 295318.

Carrère, S., Buehlman, K. T., Coan, J., Gottman, J. M., \& Ruckstuhl, L. (2000). Predicting marital stability and divorce in newlywed couples. Journal of Family Psychology, 14, 42-58.

Cherlin, A. (1981). Marriage, divorce, remarriage. Cambridge, MA: Harvard University Press.

City of Seattle, Office for Long-Range Planning. (1990). Census 1990 Population Changes in Seattle 1980-1990. Seattle, WA:

Clulow, C. F. (1982). To have and to hold: Marriage, the first baby and preparing couples for parenthood. Aberdeen, Scotland: Aberdeen University Press.

Cowan, C. P., \& Cowan, P. A. (1988). Who does what when partners become parents: Implications for men, women, and marriage. Marriage \& Family Review, 12, 105-131.

Cowan, C. P., \& Cowan, P. A. (1992). When partners become parents. New York: Basic Books.

Cowan, C. P., \& Cowan, P. A. (1995). Interventions to ease the transition to parenthood: Why they are needed and what they can do. Family Relations, 44, $412-423$.

Cowan, P. A., Cowan, C. P., \& Kerig, P. K. (1993). Mothers, fathers, sons and daughters: Gender differences in family formation and parenting style. In P. A. Cowan \& D. Field (Eds.), Family, self and society: Toward a new agenda for family research (pp. 165-195). Hillsdale, NJ: Erlbaum.

Crawford, D. W., \& Huston, T. L. (1993). The impact 
of the transition to parenthood on marital leisure. Personality and Social Psychology Bulletin, 19, 39-46.

Feldman, H. (1971). The effects of children on the family. In A. Michel (Eds.), Family issues of employed women in Europe and America. Lieden, Germany: E. J. Brill.

Krokoff, L. J. (1984). A telephone version of the Locke Wallace test of marital adjustment. Unpublished manuscript, University of Illinois at UrbanaChampaign.

Lemasters, E. E. (1957). Parenthood as a crises. Marriage and Family Living, 19, 352-355.

Locke, H. J., \& Wallace, K. M. (1959). Short marital-adjustment and prediction tests: Their reliability and validity. Marriage and Family Living, 21, 251-255.

MacDermid, S. M., Huston, T. L., \& McHale, S. M. (1990). Changes in marriage associated with the transition to parenthood: Individual differences as a function of sex-role attitudes and changes in the division of household labor. Journal of Marriage and the Family, 52, 475-486.

McHale, S., \& Huston, T. L. (1985). The effect of the transition to parenthood on the marriage relationship. Joumal of Family Issues, 6, 409-435.

National Center for Health Statistics. (1991). Ad- vance report of final marriage statistics: 1988 . In Monthly vital statistics report, 39 (12, Suppl. 2, pp. 1-20). Hyattsville, MD: Public Health Service.

Raush, H. L., Barry, W. A., Hertel, R. K., \& Swain, M. A. (1974). Communication, confict and marriage. San Francisco: Jossey-Bass.

Rogosa, D. (1995). Myths and methods: "Myths about longitudinal research" plus supplemental questions. In J. M. Gottman (Ed.), The analysis of change (pp. 3-66). Hillsdale, NJ: Erlbaum.

Waldron, H., \& Routh, D. K. (1981). The effect of the first child on the marital relationship. Journal of Marriage and the Family, 43, 785-788.

Schumm, W. R., Webb, F. J., \& Bollman, S. R. (1998). Gender and marital satisfaction data from the National Survey of Families and Households. Psychological Report, 83, 319-327.

Wright, J. P., Henggeler, S. W., \& Craig, L. (1986). Problems in paradise? A longitudinal examination of the transition to parenthood. Journal of Applied Developmental Psychology, 7, 227-291.

Received January 15, 1999

Revision received November 3, 1999

Accepted November 4, 1999 